\title{
Cannabis induced myocardial infarction underlying mechanism and the place of glycoprotein IIb/IIIa inhibitors in its management: Two illustrative cases of acute anterior myocardial infarction related to cannabis
}

\author{
Noamen $A^{*}$ Hajlaoui N, Mehdi G and Haouala $H$ \\ Cardiology Department, Military Hospital of Tunis, Tunisia
}

\begin{abstract}
Cannabis is known to have been used for medicinal purposes and recreational use to increase sociability and produce euphoria. Regular use of cannabis can have adverse effects. Cardiovascular effects are not associated with serious health problems, although occasional myocardial infarction, stroke, and other adverse cardiovascular events are described. Indeed, there is insufficient knowledge concerning acute myocardial infarction (AMI) associated with cannabis and its underlying mechanism. We reported two illustrative cases of acute anterior myocardial infarction caused by cannabis abuse to emphasize on it as the most probable causes of AMI observed in apparently healthy young persons who use this drug.
\end{abstract}

\section{Introduction}

Cannabis is known to have been used for medicinal purposes and recreational use to increase sociability and produce euphoria for thousands of years [1]. Over the past 50 years, it has been increasingly adopted by adolescents and young adults in high-income countries, and has recently become popular on a global scale. Regular use of cannabis during adolescence and into adulthood can have adverse effects. Cardiovascular effects are not associated with serious health problems for most young healthy users, although occasional myocardial infarction, stroke, and other adverse cardiovascular events are described. Indeed, there is insufficient knowledge concerning acute myocardial infarction (AMI) associated with cannabis and its underlying mechanism. We reported two illustrative cases of acute anterior myocardial infarction caused by cannabis abuse to emphasize on it as the most probable causes of AMI observed in apparently healthy young persons who use this drug.

\section{Case 1}

A 22 year old man with a family history of coronary artery disease was admitted with tight central chest pain, one month after donating a kidney for his brother. Physical examination was unremarkable. The admission electrocardiogram showed ST segment elevation in anterior leads. The patient was not taking any medications. Later on, it was determined that he had been smoking cannabis; in addition, he smoked 10-15 tobacco cigarettes per day. He was taken immediately to the coronary angiography laboratory for PCI. On coronary angiogram, it was observed that he had an extensive spontaneous coronary artery dissection of the proximal segment of left anterior descending (LAD) artery with a total occlusion of its distal segment (Figure 1). Intravascular Ultrasound examination demonstrated a dissection flap (Figure 2). We managed the patient conservatively using Glycoprotein IIb/IIIa inhibitors (Tirofiban). The peak cardiac troponine I was $9 \mu \mathrm{g} / \mathrm{L}$ and echocardiography revealed left ventricular septal and apical wall motion abnormalities and a ventricular thrombus located at the apex of the left ventricle was present. After one week, the angiographic control showed complete disappearance of the dissection. The clinical course was uneventful and the patient was discharged.

\section{Case 2}

A 37-year-old man with no relevant risk factors for coronary artery

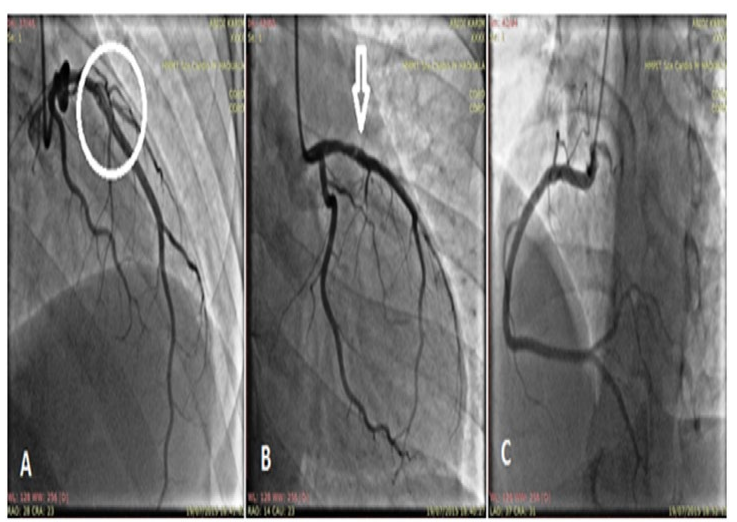

Figure 1. Extensive spontaneous coronary artery dissection of the proximal segment of left anterior descending (LAD) artery with a total occlusion of its distal segment.

Correspondence to: Aymen Noamen, MD, Cardiology Department, Military Hospital of Tunis, Tunisia; Tel: +21692661992; E-mail: no.aymen@gmail.com

Key words: cannabis, myocardial infarction, thrombosis, platelet glycoprotein GPIIb-IIIa complex, P-Selectin

Received: April 10, 2016; Accepted: May 20, 2016; Published: May 24, 2016 


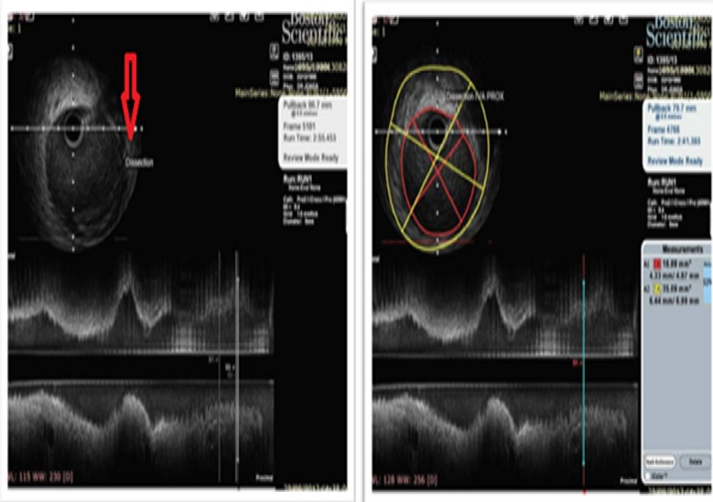

Figure 2. Dissection flap.
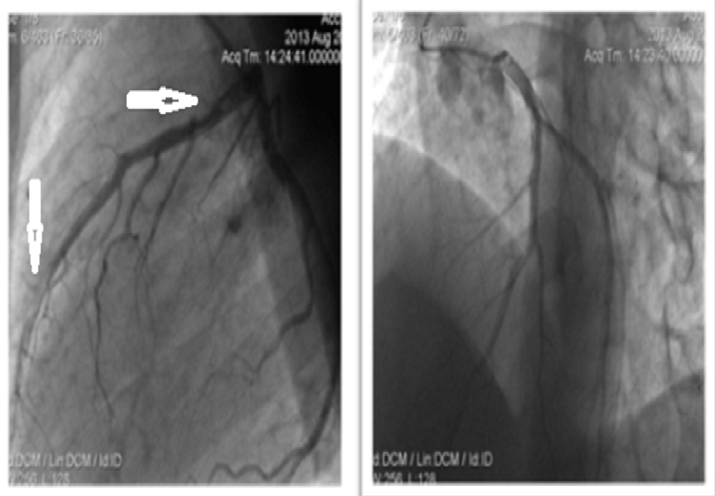

Figure 3. Panel A: a large thrombus burden grade 3 in the proximal left anterior descending (LAD)artery with dissection. Panel B and C : Circumflex and right coronary artery were angio graphically normal.

disease, other than tobacco smoking, was admitted in our intensive care unit because of retrosternal chest pain for approximately 30 minutes. On physical examination, he was distressed and sweaty, his blood pressure was $120 / 60 \mathrm{mmHg}$. An electrocardiogram showed sinus rhythm and 2-3 mm ST-segment elevation on lead V1 to V5. He smoked cannabis cigar (the last consumption of cannabis was $10 \mathrm{~h}$ ago). The patient was immediately taken to the hemodynamic laboratory because of acute anterior myocardial infarction. Coronary angiography revealed a large thrombus burden grade 3 in the proximal left anterior descending (LAD) artery with dissection (Figure 3 Panel A). Circumflex and right coronary artery were angiographically normal (Figure 3 Panel B and C). Laboratory tests demonstrated a troponine peak of $2.23 \mu \mathrm{g} / \mathrm{L}$; other values were within limits.

Echocardiography showed a normal ejection fraction with motion abnormalities in the apical segment of the anterolateral wall and the mid and apical segments of the anterior wall, an enlargement of the right chambers with a conserved function.

The patient received intravenous Glycoprotein IIb/IIIa inhibitors (Tirofiban) during 48 hours. Clinical evolution was satisfactory without new ischemic events. Angiographic control was planned but he was discharged against medical advice owing to social and financial issues.

\section{Discussion}

Cannabis contains over 400 chemical compounds and at least 60 psychoactive substances, but the main biological effects of smoking it result from delta-9-tetrahydrocannabinol (THC) and other cannabinoids (CBs) [2]. It is rapidly absorbed through the lungs. It has a plasma half life of 20-30 hours and can be detected in the urine for several days in occasional users, and for up to two months in heavy users [3]. The effects of CBs are mainly mediated by the activation of $\mathrm{CB}$ receptors. Two main subtypes of $\mathrm{CB}$ receptors have been determined and cloned ( $\mathrm{CB} 1$ and $\mathrm{CB} 2$ ). While $\mathrm{CB} 2$ receptors are localized primarily to cells of the immune system, CB1 receptors are found mainly in the central nervous system and, to a lesser extent, in certain peripheral tissues, such as the heart, adrenal gland, adipose tissue, liver, lung, and presynaptic nerve terminals [2].

The mechanisms, by which cannabis exerts its toxicity on the myocardium and the coronary vasculature, seem to be multi-factorial. THC reaches peak levels rapidly in the bloodstream during cannabis smoking [4]. It stimulates the sympathetic nervous system with a rapid and substantial dose-dependent increase in heart rate and cardiac output by more than $30 \%$ [5,6]. Increase in blood pressure can occur when sitting or supine and acute fall can occur when standing with orthostatic hypotension due to decrease in peripheral vascular resistance $[5,6]$. In addition, smoking cannabis is associated with an increase in carboxyhaemoglobin, resulting in decreased oxygen carrying capacity [6]. All these effects lead to increased myocardial workload and oxygen demand with reduced blood supply causing myocardial ischemia. Vasospasm is consequently another patho-physiological mechanism that has been suggested, particularly to explain cases of coronary or cerebral ischemia where blood vessels have shown normal conditions in the affected areas after the ischemic event [7].

The risk of myocardial infarction is almost fivefold higher within the hour after cannabis smoking, although this heightened risk seems to decline rapidly beyond the first hour [8]. Thrombosis is due to the plaque rupture in a pro coagulation environment: cannabis enhances oxidative stress with increased oxidized low-density lipoprotein formation, increased factor VII activity, activation and aggregation of platelets, and induction of an inflammatory response [5]. These expose to plaque disruption in the presence of a vulnerable, but not necessarily stenotic, atherosclerotic plaque.

In coronary patient cannabis use seems to have a more pronounced effect on triggering angina than nicotine. A controlled cross-over study has compared effects of smoking tobacco and cannabis on angina pectoris and demonstrated that smoking one marijuana cigarette significantly decreased the exercise time until angina more than smoking one high-nicotine cigarette. Exercise time until angina showed a reduction of $50 \%$ after smoking a marijuana cigarette versus $23 \%$ reduction after smoking one high-nicotine cigarette [9].

In our two patients who had no relevant risk factors for coronary artery disease, the main angiographic finding was thrombotic lesion and dissection with no evidence of atherosclerosis elsewhere in the coronary system. Both cases were managed successfully with Glycoprotein IIb/IIIa inhibitors.

We believe that the procoagulatory effect of THC in platelets is the main mechanism of the AMI. Platelets are potential target cells for cannabinoids. THC activates platelets as determined by enhanced glycoprotein IIb/IIIa expression and P selectin expression as demonstrated by the study conducted by Engelbert Deusch and al showing that the expression of activated glycoprotein IIb-IIIa $(\mathrm{P}<0.05$ at $\geq 10-6 \mathrm{M}$ THC) and $\mathrm{P}$ selectin $(\mathrm{P}<0.05$ at $\geq 10-7 \mathrm{M}$ THC) on human platelets was significantly enhanced by THC in a concentrationdependent manner when compared with control values and platelet membrane preparations were positive for both CB1 and CB2 [10]. 
It is important to know that cannabis may give rise to AMI, in apparently healthy young persons who occasionally or usually use this drug because the diagnostic and treatment approaches are different from the patient with atherosclerosis heart disease. Therefore, cannabis smoking should be added to traditional epidemiological history particularly in young patients complaining of acute chest pain. We recommend even a routine urine tests as it is detected in the urine up to two months [3] in order to take effective measures to promote the cessation of cannabis abuse and adequate treatment for dependence.

\section{Conclusion}

We should raise awareness among public about this major adverse effects and revise any suggestion to render cannabis accessible for general sale as a 'soft drug'; a present dilemma recently discussed in our parliament. But, the real challenge is to avoid such event during the palliative treatment of patients with malignancies or chronic pain, who are potentially coronary patients, because of the THC strong antiemetic and appetite-stimulating effects in conjunction with its analgesic effects $[11,12]$.

\section{Disclosure statement}

The authors report no financial relationships or conflicts of interest regarding the content herein.

\section{Human and/or animal rights statement:}

This article does not contain any studies with human participants or animals performed by any of the authors.

\section{Informed consent}

Informed consent was obtained from all individual participants included in the study.

\section{References}

1. Abel EL (1980) Marihuana: the first twelve thousand years. New York: Plenum Press.

2. Mach F, Montecucco F, Steffens S (2008) Cannabinoid receptors in acute and chronic complications of atherosclerosis. Br J Pharmacol 153: 290-298.[Crossref]

3. Ghuran A, Nolan J (2000) Recreational drug misuse: issues for the cardiologist. Heart 83: 627-633.[Crossref]

4. Lindsay AC, Foale RA, Warren O, Henry JA (2005) Cannabis as a precipitant of cardiovascular emergencies. Int J Cardiol 104: 230-232.[Crossref]

5. Aryana A, Williams MA (2007) Marijuana as a trigger of cardiovascular events speculation or scientific certainty? Int J Cardiol 118: 141-144.[Crossref]

6. Pratap B, Korniyenko A (2012) Toxic effects of marijuana on the cardiovascular system. Cardiovasc Toxicol 12: 143-148.[Crossref]

7. Bachs L, Mørland H (2001) Acute cardiovascular fatalities following cannabis use Forensic Sci Int 124: 200-203.[Crossref]

8. Mittleman MA, Lewis RA, Maclure M, Sherwood JB, Muller JE (2001) Triggering myocardial infarction by marijuana. Circulation 103: 2805-2809.[Crossref]

9. Aronow WS, Cassidy J (1974) Effect of marihuana and placebo-marihuana smoking on angina pectoris. N Engl J Med 291: 65-67.[Crossref]

10. Deusch E, Kress HG, Kraft B, Kozek-Langenecker SA (2004) The procoagulatory effects of delta-9-tetrahydrocannabinol in human platelets. Anesth Analg 99: 11271130.[Crossref]

11. Moroi K, Sato T (1975) Comparison between procaine and isocarboxazid metabolism in vitro by a liver microsomal amidase-esterase. Biochem Pharmacol 24: 1517-1521. [Crossref]

12. Kumar RN, Chambers WA, Pertwee RG (2001) Pharmacological actions and therapeutic uses of cannabis and cannabinoids. Anaesthesia 56: 1059-1068.[Crossref]

Copyright: $\odot 2016$ Noamen A. This is an open-access article distributed under the terms of the Creative Commons Attribution License, which permits unrestricted use, distribution, and reproduction in any medium, provided the original author and source are credited. 